\title{
Réflexions sur l'ethnologie médicale, l'excision et la «compréhension» culturelle
}

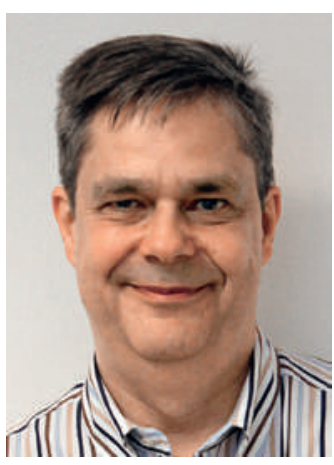

Eberhard Wolff
Lorsqu'un ouvrage a comme sous-titre «Introduction», on s'attend à une synthèse pondérée sur l'état des connaissances et des débats dans le domaine. C'est un peu différent pour l'ethnologie médicale, qui ne constitue ni une discipline bien établie, ni un canon clair de la connaissance. L'ouvrage d'introduction à l'ethnologie médicale, dont il est question ici [1], vient d'être publié pour la quatrième fois avec un texte complètement remanié.

L'un des grands principes de l'ethnologie médicale consiste à montrer que «d'autres personnes dans le monde peuvent voir les choses tout à fait différemment de nous» (d'après Wolfgang Bichmann, dans son avant-propos). En prenant en compte le contexte dans lequel s'inscrit un comportement lié à la santé, nous pouvons mieux comprendre les autres cultures (donc nous-mêmes naturellement).

C'est justement ce principe que l'ethnologue et éditrice de l'ouvrage, Katarina Greifeld, tente d'appliquer, sur un thème où la «compréhension» est tout ce qu'il y a de plus difficile pour beaucoup d'entre nous: le sujet «explosif» de l'excision du clitoris et/ou des petites lèvres, telle qu'elle est pratiquée en Afrique de l'Ouest et du Nord-Ouest. Des mots qui nous donnent la chair de poule et évoquent toutes les idées véhiculées en permanence par le débat public: mutilation, violence faite aux femmes, atteinte aux droits de l'homme et aux droits fondamentaux de l'enfant, influence néfaste de l'Islam et de la tradition. En un mot, un scandale. Pourtant, pour K. Greifeld, le thème de l'excision est «depuis des années pollué par les émotions et peut difficilement être débattu en public sans que soit introduit un jugement de valeur.» Selon elle, il faudrait être un peu plus objectif et un peu moins passionné. Ne serait-ce qu'avec la notion accusatrice de mutilation, elle estime «qu'on ne respecte pas le point de vue des femmes qui veulent l'excision, pour elles-mêmes et pour leurs filles». L'ethnologue appuie son argumentation sur une étude réalisée au Mali, pays d'Afrique de l'Ouest où près de $90 \%$ des femmes sont excisées. Cette enquête analyse également les justifications avancées en faveur de l'excision.

Voici en résumé les conclusions que K. Greifeld tire de ces résultats: oui, il s'agit de contrôler la sexualité féminine, mais pas de la nier. Oui, l'excision est souvent justifiée par la religion islamique, mais elle est aussi pratiquée en dehors de l'Islam. Outre la tradition et la religion, l'une des motivations pour l'excision est la norme sociale, selon laquelle seule une femme excisée serait une véritable épouse, qui ne soit pas infidèle et ne porte pas atteinte à l'honneur de la famille. Oui, il s'agit aussi de l'exercice du pouvoir masculin et de celui de décider de la façon dont doit être l'appareil génital féminin. Mais K. Greifeld met en doute l'idée selon laquelle la majorité des Maliennes considéreraient l'excision comme un traumatisme durable.

Notre critique de l'excision serait-elle alimentée par notre vision néocolonialiste des «sous-développés»? Cette critique porte d'ailleurs sur une pratique largement légitimée au XIX ${ }^{\mathrm{e}}$ siècle, sous nos latitudes, d'un point de vue médical. L'ethnologue tient ce raisonnement et aborde un thème qu'elle reconnaît être délicat: est-ce que cette critique de l'excision ne transfère pas le concept d'orgasme des pays nantis du Nord aux autres cultures, oubliant que la culture influence tout autant la sexualité que le corps, comme le pensait Foucault? Existe-t-il au Mali des expériences sexuelles différentes de celles des nantis du Nord? D'autres sujets comme la sécurité seraient-ils plus importants pour les femmes maliennes, et l'excision ne serait-elle pas synonyme «de propreté et d'autocontrôle», de beauté et de «respectabilité sociale», sur la base de leur conception de l'intimité?

Ce qui m'intéresse dans l'approche provocante de K. Greifeld est le principe fondamental: les émotions sont stimulantes, mais elles peuvent aussi cacher des opinions différentes. A ce propos me vient toujours à l'esprit l'image des bébés phoques exploitée par les associations de défense des animaux. Pour comprendre que tout n'est pas si simple, à mon avis, les points d'interrogation sont bien plus utiles que les points d'exclamation. Comprendre n'équivaut pas à légitimer. Réfléchir pour comprendre ne revient pas à minimiser, mais permet de mieux analyser. Si on peut analyser une question de façon plus nuancée, la critique devient alors plus limitée et plus précise, plus réfléchie et plus prudente. Et les implications générales ne concernent pas seulement la «lointaine» Afrique. Prenons un exemple tout à fait d'actualité: ce n'est qu'en analysant minutieusement les arguments des détracteurs de la vaccination et de ceux qui sont sceptiques sur le sujet que l'on pourra réagir de façon adaptée. Une ethnologie de notre propre culture pourrait tenter de nous aider à «comprendre». Le passage à la prochaine question, encore plus importante, devient alors plus clair: où est la ligne rouge de la «compréhension» culturelle? Cette limite nous a été clairement révélée il n'y a pas si longtemps avec la Shoah. Mais ne commençons pas par la fin.

Eberhard Wolff* 